\title{
Erratum to: Respiratory diphtheria due to Corynebacterium ulcerans transmitted by a companion dog, Italy 2014
}

\author{
Monica Monaco ${ }^{1} \cdot$ Anna Rita Sacchi $^{2} \cdot$ Marzia Scotti $^{3} \cdot$ Fabiola Mancini $^{1}$. \\ Carlo Riccio $^{2}$ - Giulia Errico ${ }^{1} \cdot$ Giovanna Ratti $^{3} \cdot$ Filippo Bondi $^{3} \cdot$ Alessandra Ciervo $^{1}$. \\ Annalisa Pantosti ${ }^{1}$
}

Published online: 7 August 2017

(C) Springer-Verlag GmbH Germany 2017

\section{Erratum to: Infection}

DOI 10.1007/s15010-017-1040-1

Owing to an unfortunate error in typesetting, the correct term "diphtheria" was replaced by "diphtheriae" throughout the text of this article. The publisher apologises for this error and the inconvenience caused.

The original article has been corrected.

The online version of the original article can be found under doi:10.1007/s15010-017-1040-1.

\footnotetext{
Monica Monaco

monica.monaco@iss.it

Istituto Superiore di Sanità, Rome, Italy

2 Azienda Unità Sanitaria Locale, Piacenza, Italy

3 Ospedale Guglielmo da Saliceto, Piacenza, Italy
} 